\title{
HOMEM, QUEM ÉS, O QUE ÉS?*
}

Fernando de Azevedo

$<O$ homem> ataca e mata. Sem ter fome e sem ser atacado. Outra característica do homem: linguagem articulada $e$ faculdade de rir. O homem, um animal que fala e um animal que ni. Que fala, freqüentemente mal como estou falando agora, mas o que é pior, tem o hábito de falar muito mal dos outros, hábito que eu não tenho.

A faculdade de rir: o homem é um animal que ri. O riso é uma linguagem também. Reparem vocês, que o homem năo precisa falar para exprimir as suas idéias, seus sentimentos, suas reaçōes. Rindo e pela maneira de nir ele diz tudo e, às vezes, a ponto de desconsertar a gente, só pelo rir; a maneira de rir. Agora, o riso também é uma linguagem que sublima, que marca, que desenvolve, que associa, que sublinha a própria linguagem articulada. Quando falamos vamos (podemos dizer) sublinhando, acentuando, assinalando, marcando mais as nossas palavras, nossas idéjas e nossos sentimentos pelo riso, pela maneira de rir. Emesmo sem falar nós podemos exprimir muita coisa, muito de nosso sentimentos, nossas reaçōes, apenas rindo.

$<$ Há> nisos de toda ordem: o riso amável, sorriso; o riso, o riso motejador; riso de desprezo e riso agressivo. Nós podemos responder ou agredir uma pessoa pela maneira de rir e a pessoa se ofende mais do que quando falamos.

Eu tinha anotado duas observaçōes muito interessantes para vocês, mas estāo me escapando. A memória, às vezes e até freqüentemente, é traiçoeira, arisca e fugitiva. Mesmo a gente puxando pelas orelhas näo consegue obtê-la, fazê-la presente quando a queremos. Agora, por exemplo, já por duas vezes ela me escapou.

Estou fazendo com certa dificuldade <esta palestra> por não estar me sentindo bem, como declarei ao Professor Antonio Candido. Mas achei que tendo me

- Texto inédito de aula ministrada em 11 de março de 1973. Promoção IEB, Anfiteatro de História. Prédio Geogradia e História/USP. Transcriçāo realizada por Júlio Augusto F. C. Farias e Maria Helena Pinoti Schiesari. Docum. Atividades do IEB. Arquivo/IEB. 
comprometido a falar hoje e tendo vocês, moças e rapazes, tido para comigo a gentileza de acudirem para me ouvir, eu devia falar, não podia fugir deste compromisso, ainda que falando mal, me exprimindo mal, com certa dificuldade e tensão nervosa. Mas, dizia então, nós temos uma tal capacidade de nos exprimir pelo riso que, às vezes, nos dispensamos de falar. E agradamos sorrindo... Tanto podemos agradar sorrindo, como desagradar, ferir, agredir, sorrindo ou nindo, sem falar, portanto.

Agora, falando dessas características do homem, linguagem articulada $e$ capacidade de rir: o riso às vezes é supletivo da linguagem, pode substituir a linguagem e substitui muito bem. Agora, uma outra característica do homem que é muito interessante (que o define na escala animal afastando-o de todos os outros tipos): 〈enquanto> os animais agarram, o homem, além da linguagem articulada $e$ do riso, tem a capacidade de apor o dedo polegar ao indicador. É desta maneira que escrevemos. É desta maneira que se costura, que se escreve, é dessa maneira que se pode usar uma arma de fogo. Os outros indivíduos da escala animal agarram, só usam as mãos para apreender, não têm essa capacidade delicada de apreensão ajustando o polegar ao dedo indicador; esta é característica do homem.

Eu tinha anotado, além disso, uma coisa. Não trouxe. Era uma observação que eu tinha feito em casa e que queria ler a vocês, mas estou vendo que nāo trouxe comigo. Mas então, vamos resumir. A primeira característica do homem: cabeça alta, olhos para cima, quando os outros animais têm cabeça baixa e os olhos, geralmente, para frente, porém para baixo, não para cima. Cito aquele verso de Ovidio: "Deus deu ao homem um nobre aspecto. Mandou olhar para o céu e ter o rosto voltado às estrelas".

<Assim, é a partir> desta capacidade de se exprimir pela linguagem articulada e pelo sorriso que os homens podem comunicar-se entre si, com os individuos das suas gerações e das diversas geraçōes que se sucedem no tempo. Pois veja, pela linguagem articulada a gente pode recolher através dos séculos, dois, três, quatro mil anos, todos os conhecimentos e experiências acumuladas pelo homem, que foram transmitidas pela linguagem falada e depois pela linguagem escrita, mais tarde pela imprensa e agora pelos meios modernos como o rádio e a televisāo. Essa aposição do polegar com o indicador, com o qual ele pode praticar os atos mais delicados como por exemplo escrever - nós temos uma maneira de escrever com os dedos da mão direita ou esquerda sempre com o polegar e o indicador - e a maneira de apreender as coisas, uma apreensão fácil, delicada, a de escrever, <a de> costurar; e também para matar, tomar um gatilho, acionar o gatilho de uma arma de fogo.

Depois de ter <falado> a respeito das características do homem - cabeça alta, olhos para frente, linguagem articulada, a capacidade de rir, a gesticulação e essa capacidade de ligar o dedo polegar ao indicador, coisas que nos permitem escrever, costurar e usar armas de fogo - eu gostaria que os senhores fizessem perguntas para 
esclarecer qualquer desses pontos ou entăo apresentar suas objeçōes ao que acabo de dizer. Acho que uma conferência, uma palestra não está completa sem estabelecer o diálogo de quem fala, de quem está com a palavra e daqueles que estão ouvindo. Nāo façam cerimônia não, por favor. Há alguma objeção a fazer? Alguma pergunta interessante a que eu possa dar a reposta sobre esses itens? Estou com uma cara feia hoje? Está ótimo? Parece, porque ninguém fala! Agora a moça está fazendo uma pergunta, pois não.

\section{O senhor näo fez referêncla ao pensamento do homem.}

Mas... Olha aqui, filha, eu não fiz referência ao pensamento do homem porque está incluso a tudo que eu acabei de dizer! Repare bem: a cabeça alta e sempre disposição de olhos para cima; a linguagem articulada. Quando falo de linguagem articulada, ao falar em sorrir e rir, está claro que está incluso o pensamento do homem, porque o homem fala, e quando fala está pensando, pensa antes, e mesmo pensando mal, está pensando, quando fala. E quando fala também tanto no sorrir quanto no rir, está incluso o pensamento. Ele é impelido a falar e a rir pelo pensamento, pensando. Ninguém fala sem estar pensando ao mesmo tempo. $O$ fato de falar implica a idéia de pensar, como o fato de sorrir e de rir. Ninguém ri ou sorri sem pensar, sem estar pensando, sem ser por força de um pensamento ou idéia que lhe ocorreu. Está bem? Que mais? Fale filha! Pode insistir na objeçăo, diz que não está satisfeita! Está satisfeita? Vamos a outro.

Eu gostaria que o senhor explicasse sobre a capacidade do homem de não se submeter à natureza, transformando-a para viver.

Não se submeter à natureza transformando a natureza... Esta é uma observação muito interessante. Porque o homem não é também o único animal que não se submete à natureza por querer transformá-la. Porque os outros animais também o fazem. Todos os outros animais. Quando fazem sua toca, eles se dispōem a acomodar-se na sua casa, na casa que eles mesmos constroem. Eles estão modificando a natureza, a paisagem, eles năo se adaptam à paisagem sem um esforço natural para adaptá-la às condições de sua vida.

Agora, o homem, não. O homem não só se acomoda à natureza, mas procura estar constantemente trabalhando no sentido de transformar a natureza. E ele precisa da natureza para suas construções. Nós, por exemplo, estamos falando numa sala. Esse edifício é construído onde havia uma paisagem. Ele destrói a paisagem para levantar suas construçōes neste e naquele sentido: edifícios, postes, elevadores, tudo que é construção humana se faz a partir de sacrificio da paisagem. Destrói a paisagem para construir o que the interessa no momento, dispondo da natureza em seu favor, em seu benefício, para atender aos seus interesses imediatos. Esta é a capacidade do homem de transformar. O homem é o único animal que destrói constantemente 
a natureza para fazer, para construir, para criar, para realizar as suas criaçōes. Os outros animais, os outros individuos da escala animal transformam também a natureza, mas em dimensão muito restrita, apenas para acomodar, para condicionar, para melhorar as condiçōes do seu habitat. O homem não. Entăo? É isso?

Prof. o senhor pediu à moça que fizesse objeções as suas palauras para provocar esse diálogo. Entāo quero fazer a minha objeçāo. Eu sou arquiteto, $e$ a função do arquiteto não é destruir a paisagem, mas melhorar a paisagem. Nossa intenção não é destruir a paisagem, pelo contrário, é melhorar a palsagem, nós construímos com esse objetivo.

O arquiteto destrói sim a paisagem para construir; depois levanta, restabelece a paisagem para atender aos interesses da sua construção. Destrói a paisagem porque ele não pode construir sem destruí-la.

\section{Eu continuo fazendo objeção.}

Depois de destruir a paisagem ele constrói. Destrói para construir. Depois levanta a paisagem para guarnecer, dar mais beleza à sua própria obra de arquiteto.

Mas a obra do arquiteto nāo visa sua vaidade, ele faz para servir ao homem. Então, está criando uma nova paisagem que agrada ao homem.

Certo! Que agrada ao homem.

Entāo não está destruindo, está construindo uma nova paisagem.

Está construindo uma nova paisagem exatamente para agradar ao homem. Exemplo: as praias de Santos, a praia da llha Porchat. Os arquitetos, há uns quinze anos atrás, começaram a construir uma paisagem maravilhosa. Até que os arquitetos, mais recentemente, com comerciantes, fizeram aquela coisa horrorosa que săo aqueles prédios nas encostas, nos sopés e no topo da ilha. Deturparam completamente <o projeto> e ficou aquela monstruosidade.

Agora, se me permite, isso não é obra propriamente dos arquitetos. É obra das grandes empresas construtoras. A culpa é dos engenheiros, porque os prédios são tão mal construídos que não se pode lançar a responsabilidade aos arquitetos, mas ao engenheiro que faz o prédio; os engenheiros que estão a serviço dessas grandes empresas e que fazem um projeto, como já disse, uma obra que visa os interesses imediatos da empresa. Nāo é propriamente o arquiteto. Arquiteto é o engenheiro que tem as suas vistas voltadas para o planejamento de uma obra, não só dentro das condiçōes da paisagem, mas que seja, também, uma obra de arte, não $e ́$ isso? E o engenheiro não está se preocupando com a obra de arte. Está fazendo uma obra que possa interessar aos indivíduos que o contrataram e interessar a ele, projetista, realizador e executor daquela obra. 
Você me dá licença de responder à agressão do Professor Araújo? Continuando o meu ponto de vista, quando fiz o meu protesto aqui ao Prof. Fernando de Azevedo, me referl aos arquitetos em tese. Evidentemente, todos os arqultetos são humanos e cometem erros como todo homem e muitas vezes o arquiteto consegue destruir a paisagem e construir "monstros" que prejudicam a paisagem ao invés de melhorá-la. Mas eu defendo isso em tese: o objetivo do arquiteto é criar novas palsagens que sirvam ao homem. Agora, quanto aos paredōes de Santos e da Ilha Porchat, eu também estou de acordo com o professor Araújo e também não acusaria os engenhelros, eu acuso a vida que nós levamos de exploraçāo Imobiliária. Então, os interesses Imobillários é que vão avançando, avançando descontroladamente e destroem a paisagem, $e$ destroem até o nosso conforto.

O homem modifica a paisagem natural, construindo uma paisagem através do seu artifício...

Eu não digo artifício <mas sim> pela sua capacidade de imaginar e <pela> capacidade de criação. Mas não é propriamente artifício, não. Não acha?

Eu queria fazer mals uma "defesasinha", pois afinal de contas ful fazer uma intervenção e passel a ser o alvo de todas as críticas...

Com todo prazer para nós e para todos.

Eu vou dar uma informação aos presentes: aqui em Sāo Paulo, das construçōes que se fazem, não chegam a $5 \%$ as que têm a assinatura de um arquiteto. Entāo, a nossa responsabilidade é relativamente pequena na destruiçāo das paisagens.

É muito pequena sim. São dos engenheiros,não é?

Nāo quero acusar ninguém...

Mas é do engenheiro sim... Muitas vezes o que destrói não é a construçăo, é a intenção de exploração imobiliária que nāo respeita interesse nenhum a não ser este objetivo.

Eu nāo me referi às firmas, eu me referi à exploração imobiliária. Năo é a firma, não é o arquiteto ou o engenheiro que são os responsáveis. Como você disse, nós não temos uma organizaçāo preparada para isso. Entāo, os interesses imediatos vão se sobrepondo a tudo e as paisagens vão sendo destruídas.

Nós, arquitetos e engenheiros, vamos lutando pela liberação de planos, desses planos que defenderiam esses arquitetos. Se nós fizéssemos tudo planejado, limitaríamos muito a destruiçāo da paisagem. É que nossas coisas 
são feltas por interesse momentâneo, sem uma regulamentaçāo, sem uma fiscalizaçāo maior. Então, elas vão destruindo as paisagens...

O verde! Reduzindo a área verde da cidade.

O senhor já disse que partiu traçando observaçāo em torno da possibllidade de se falar sobre a concepçāo de progresso científico.

De uma determinada concepção de progresso, mas concepçāo que pode, por exemplo, agradar a uns e desagradar a outros, mas, em todo caso, é uma dessas concepções de progresso. O progresso não é visto da mesma maneira e de maneira igual por todos os olhos. Cada um vê o progresso a sua maneira, segundo a sua concepção de vida.

Há a possibilidade, então, de prever para prover?

Há sempre essa possibilidade de prever para prover. Agora, previsões a curto prazo.

\section{Ou a longo prazo?}

Não, a curto prazo. A longo prazo eu me perguntaria: A longo prazo como? $O$ que se pode prever para daqui a cem anos?

Agora, quem mais tem alguma objeção a fazer? Aquele rapaz ali. Seu nome por favor?

\section{Marcos Sérgio.}

Marcos Sérgio, podia falar um pouco mais alto por favor?

No campo das ciênclas físicas, atualmente, existe a possibilidade de se prever multo melhor que no campo das ciências humanas...

Não, parece-me que não. A capacidade de prever no campo das ciências humanas não é grande. E também acho que mesmo no mundo da física, da química e da biologia, esta capacidade de perceber, de prever, também năo é. A capacidade que o homem tem de prever é muito reduzida. E nós vemos, a cada momento, os erros que se cometem por ter escapado ao homem a visão do futuro. Nāo está suficientemente desenvolvida a sua capacidade de previsão. Eu perguntaria ao senhor, respondendo às suas observaçōes: o que o senhor podia prever, por exemplo (nós estamos nos idos de 1973), para 2000? Até hoje tem se falado bastante no fim do mundo, não é? Eu me lembro de trabalhos que li referentes ao ano 1000 , a humanidade tremia de susto quando se aproximava o ano 1000. Porque se entendia, naquela época, que o ano 1000 era o fim do mundo. E você vê que, passados 973 anos, este mundo ainda está bem disposto! 
Dos 1000 passará, aos 2000 nāo chegará!

Chegaremos sim, quer dizer, chegarão vocês, eu não espero chegar a tanto! Eu não chegarei até lá, mas chegarão vocês e passarāo dos dois mil. Não se pode estabelecer nada.

O senhor não acha, professor, que nós nāo podemos prever tudo, mas podemos prever alguma coisa? E a vida imediatista que nós estamos levando hoje indica este pensamento no futuro, este pensamento de previsāo. Então multas das faltas de previsāo nāo sāo conseqüencia natural das colsas, são conseqüência da falta de preocupaçāo em prever. E por isso nós, arqultetos, nós engenheiros também, sempre propomos os planejamentos, porque se as coisas crescem espontaneamente, crescem com defeitos, que nós podemos evitar se fizermos previsōes. Entāo a técnica, a física, pode prever certas coisas exatamente certas. Mas em multa coisa da nossa vida natural podem ser evitados os erros, podem ser evitados se nós fizermos um pouco de previsão $e$ se tivermos a preocupaçāo de prever.

A previsaao, esta capacidade de previsão é tăo falha... Em matéria de saúde e de vida, eu tenho tido notícias de coisas verdadeiramente surpreendentes. O médico, por exemplo, examina a pessoa $e$ a acha bem de saúde... "você não tem nada, talvez preocupaçōes, está em perfeita saúde, tem um bom coraçāo, pulmões de menino!" O "menino" sai e vai embora. Eh, previsão médica... Ou então, previsão de morte próxima, $e$ a pessoa vai vivendo através de anos, tendo sido prevista a sua morte. Inclusive tem um caso comigo mesmo. O senhor está me vendo daí, năo? Parece que estou com saúde relativa, falando de pé, sem ares de grande cansaço, talvez com alguma fadiga, mas sem ares de grande cansaço. No entanto, se eu tivesse atendido a dois médicos, que ouvi na ocasiāo, médico a quem eu procurara e outro a quem minha familia me encaminhara para novo exame, tal o sofrimento causado em todos da casa pelo prognóstico do médico, eu já tinha morrido há cinquenta anos. Parece-me que estou me saindo muito bem. Há cinquenta anos, não dava vida para meses. O diagnóstico era muito severo. Então, todos nós erramos, e é muito difícil, mesmo para um médico, prever. Prever um estado, a nāo ser estados graves e muito graves; aí se pode fazer previsöes. Mas, o indivíduo relativamente bem, fazer previsōes a respeito do coraçăo, dos pulmões...De repente, não, a pessoa vai ao médico, que o acha muito bem de saúde, diz: "Você não se preocupe com isto". "Está bom, o senhor é o médico". Um grande médico, um grande clinico, com uma boa, uma grande reputação $e$ muito justa, que conseguiu a custo de grande esforço e seriedade, trabalho na profissão. Mas vai o doente ao médico, este doente acompanhado da mulher. $O$ médico examina, acha o estado de saúde excelente. Faz todos os exames aconselháveis quando a família está muito preocupada e o suposto doente também com seu estado de saúde; vai ao médico com sua familia. 
Isso é fato exato que eu conheci. Vai ao médico, um dos maiores médicos do Rio de Janeiro. O médico examinou atentamente, achou que o coraçāo e o pulmão eram de menino, estava tudo muito bem, que năo tinha que se preocupar com isso, que fosse pra casa, que desse uma volta pela cidade e depois fosse lá para Petrópolis, Teresópolis, ou uma dessas cidades serranas, para se distrair e esquecer, pois, parecia estar preocupado demais consigo, para se esquecer. Muito bem. Aquela senhora que estava preocupada ficou satisfeita, tomou-o pelo braço, despediu-se do diretor, ou melhor, do médico; quase que o acariciava de tanta alegria, diante do diagnóstico e do prognóstico e sai. Ele vai até a porta, a senhora avisa à teleforista, à secretária do médico, para telefonar para tal garagem para chamar um automóvel. Eles descem, o automóvel pára à porta, o médico chega até o seu paciente. Quando ele põe o pé no automóvel para ir para casa, cai morto.

\section{(Pergunta nāo entendida)}

Objetividade. Objetividade de análise e reflexão. Não admitir nada de verdadeiro, de verdade ou de possivel verdade, a não ser depois de um exame atento ou objetivo. Ciência para mim é objetividade de exame e reflexão madura sobre o que se viu observado. Objetividade, se me permite, é a submissão ao objeto. Isto que é objetividade.

\section{Seria possivel essa objetiuldade sem relóglo e sem calendário?}

Eu não gosto de calendário por causa de idade, não é? Agora, eu também não gosto muito de consulta ao relógio. Quando vou trabalhar, por exemplo, em casa, eu tenho um relógio no quarto, comigo. Mas não o consulto. Acerto o relógio pelos deveres da casa, as necessidades da casa, no trato com a empregada, hora de refeição etc. Mas eu mesmo nāo consulto o relógio. Quando eu vou trabalhar, vou trabalhar sem hora. Acabei de jantar, quando me disponho a trabalhar, sento à mesa para trabalhar sem ver a hora em que me sentei à mesa e sem preocupações com a hora de acabar. Portanto, não gosto muito de relógio, não.

Se eu tenho um compromisso para estar presente a uma hora determinada, estou atento à hora pelo compromisso que assumi, para não faltar ao compromisso assumido...

E vale a pena integrar-se tanto na sociedade ? Näo é melhor a gente viver cada um a sua própria vida? Eu não tenho muita preocupação com a sociedade, nunca tive. Mesmo para trabalhar nunca me preocupei muito. Assumi cargos de direçăo e projetei reformas e algumas reformas radicais, e nāo me preocupei muito com a sociedade, como a sociedade reagiria diante do impacto de reformas radicais que promovi. Essa luta eu procurava sustentar e tive lutas fortes, muito duras e, algumas vezes mesmo, tempestuosas, por não me preocupar muito com a sociedade. Se eu tenho que fazer reformas, eu penso, naturalmente, no que conclui mais naquele 
ponto de vista, naquele tópico, por exemplo, nos de educação e cultura. No campo da educaçăo, que reformas eu teria que fazer, teria que promover. Promovendo essas reformas, eu sei que a sociedade reagiria em certos pontos bem, ou poderia reagir mal e de maneira, às vezes, agressiva, impedindo a execução das reformas planejadas. Ao insistir, muitas vezes, a sociedade acaba cedendo. Eu posso dizer isso... No Rio de Janeiro, quando eu fui Diretor Geral da Instruçăo Pública por 4 anos, claro que com um grande apoio do Presidente e do Prefeito, eu fui muito atacado pelos jornais durante dois anos. Atacado, agredido, às vezes atacado duramente, num peńodo de dois anos, por causa das reformas que estava empreendendo. E os jornais, naturalmente, movidos pelos grupos interessados, mas contrários às reformas, atacavam-me com uma grande violência.

Deixei passar e continuei a fazer a mesma coisa, e quanto maior o ataque, maior a minha vontade de insistir, custe o que custar, quanto custar e a quem custar. Dois anos depois, esses jomais que mais me atacavam, que mais me agrediam, passaram a me apoiar integralmente e sem reserva. Aí, já não precisava tanto do apoio deles, porque o que eu tinha que fazer de mais importante e radical já estava feito. Mas passaram a apoiar-me sem reserva durante os dois últimos anos. $\mathrm{Ou}$ porque entendiam, a maior parte deles, que eu estava certo nas reformas que planejava e procurava executar, ou por cansaço, porque também agressāo cansa, não é? Não só cansamos quando somos agredidos, mas aqueles que nos agridem acabam cansando de agredir, e voltam para as suas casas para dormir um bom sono na rede.

Eu gostaria que o senhor ligasse a noção de homem que o senhor tem, com a situação da educaçāo brasileira hoje, ou seja, o senhor caracterizou o homem como um animal capaz de se exprimir, e essa expressāo revela um pensamento, a capacidade de pensar do homem. A educaçāo, talvez por estar diretamente ligada à problemática do homem, naturalmente, está envolvida nesta concepção do homem. Também gostaria que o senhor dissesse como vê os rumos da educação brasiletra hoje, se ela está mats voltada para uma atitude de colaboração.

O senhor me pergunta, entāo, como eu vejo os rumos da educação brasileira hoje? Gostei muito de ouvi-lo, foi um prazer ouvi-lo; o que o senhor está me pedindo é um assunto de conferência. Como nós estamos vendo o rumo que toma a educaçăo brasileira hoje. Se é que ela está bem "rumada" ou "arrumada". Eu não sei. Estou vendo que as coisas estão tão confusas em matéria de educaçăo, educação em todos os graus, de todos os tipos: educaçāo da infância, educaçāo da adolescência, educação na universidade $e$ todos os tipos. Eu acho que está tão confuso tudo isso, que não me abalaria a dar uma opinião. O que eu vejo em matéria de educação, hoje, é extremamente confuso. Se o senhor puder me esclarecer sobre o que se passa na educação, na educação brasileira, a situação atual $e$ os rumos que pretende 
tomar, ou a direção que, me parece, estão inclinados a dar a essa educaçăo, eu ficaria satisfeito, porque eu não estou compreendendo.

\section{É exatamente este depoimento que eu gostaria de conhecer.}

Eu posso fazer depois. Eu posso até fazer uma conferência aqui. Uma conferència sobre educação brasileira. Seria interessante promover, então, um curso de conferèncias. Convidarmos 6 ou 8 pessoas para fazer conferências aqui. Eu me comprometeria a fazer uma delas. Porque o problema é tão complexo e de tamanha extensão, que não se pode abordar todo o problema em uma conferência, só em uma série de conferências. Interesses de várias pessoas, porque daria a maneira de ver de cada pessoa, ver os mesmos problemas. Maneiras diferentes de encarar os problemas. Cada um tem o seu modo de ver, sua concepção de educação e dos rumos que the pretendem imprimir. Seria interessante para uma série de conferências aqui...

Está acelto, e o senhor tem a incumbência de fazer uma delas.

Está entendido. À disposiçăo dos senhores...

Há uma gente que às vezes bate à porta: Uma esmolinha pelo amor de Deus! E eu estou dizendo: Uma objeçãozinha pelo amor de Deus! Façam.

Essa incapacidade do homem de prever nāo estaria ligada às características do homem? Uma pequena história da estupidez humana?

Pois é, devemos ter a própria? Eu não escrevi sobre estupidez humana, porque acho o homem, a inteligência do homem, uma tamanha capacidade que o homem tem de encarar e superar as dificuldades e tamanho poder de criaçāo, que nunca acabaria na estupidez humana. A estupidez é de individuos, de individuos humanos, individuos. Mas o que há de mais admirável no homem é a sua inteligência e capacidade de criaçăo.

\section{Quem és, o que és.}

Bom, o ato de mudar e reconhecer as limitaçöes do homem. Eu acho que o homem tem uma parte de inteligência, um poder de criação, e realizou, em todos países, em todas as épocas, há três, quatro mil anos, uma obra tamanha - obra de civilizaçāo -, que procura encarar mais a sua capacidade de inteligência devido ao seu poder de criaçāo, do que as limitações dessa inteligência. Que limitaçöes podemos dizer da inteligência humana, quando nāo temos um ponto de comparação? Antes da gente estabelecer as limitações de uma inteligência, é preciso conhecer outro tipo de inteligência, superior à do homem. Outro tipo de inteligência, nāo vejo. Que outro tipo de inteligência? O homem realizou uma tal obra - quatro, três, quatro mil anos - que em todos os sentidos, mostrou, atravessando uma experiência de 
todos os povos até hoje, experiência de tal maneira enriquecida, que hoje já não falamos apenas diretamente às pessoas, podemos falar à distância com qualquer pessoa. Essas viagens... o rádio, a televisão, que nos trazem para casa tudo que se passa fora por um pequeno aparelho. $E$ depois, as viagens astronáuticas, viagens planetárias. Quem quer mais inteligência do que isso, uma inteligência, um poder de criação, aliado a um extraordinário poder de...

\section{Prever!}

Não, de prever nāo! Um poder de... Um extraordinário poder de criaçăo e uma extraordinária capacidade de resistência. Porque isso de subir, entrar numa... Como se chama? numa cápsula, e fazer uma viagem e ficar, por exemplo, semanas, e chegar até a lua, descer à lua. Que inteligência do homem! Descer à lua e percorrer, através de um pequeno automóvel, um veículo motorizado, percorrer parte da lua e depois voltar e dar notícias da lua; ai se dirá: Mas isso é lunático! Quer dizer, antigamente era lunático. Hoje esta palavra perdeu o sentido.

Eu sugeriria que nós interrompêssemos o debate, porque há uma hora e mela já <estamos conversando>.

Não, eu estou à disposiçāo...

É que o senhor comunicou de iníclo que não está bem de saúde hoje...

Não estou, agora fiquei bom! Eu não estava bem mesmo, por isso avisei antes de começar, mas em contato com vocês fiquei bom. Estou à disposiçāo. 


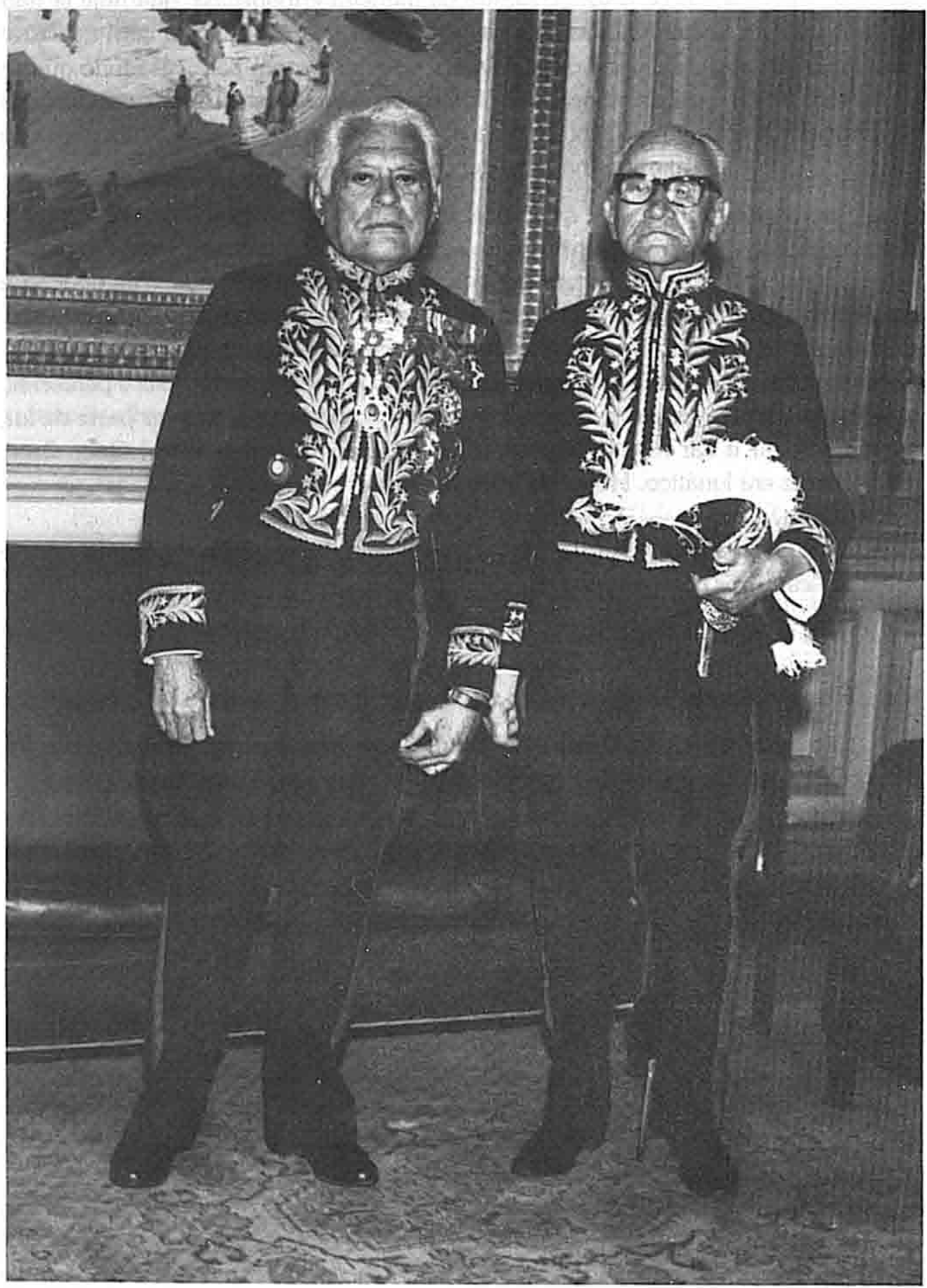

Fernando de Azevedo/Austregésilo de Ataide. Posse na Academia Brasileira de Letras, 24 set. 1968. 